\title{
Structural analysis of corpus of the lawful infliction of harm to the environment under circumstances precluding criminality
}

\author{
Svetlana Zakharova ${ }^{1}$, Ludmila Novikova ${ }^{1, *}$, Svetlana Maltseva ${ }^{2}$, and Victor Merkuriev ${ }^{3}$ \\ ${ }^{1}$ Academy of the Federal penitentiary service of Russian Federation, 1 Sennaya str., Ryazan, 390000 , \\ Russian Federation \\ ${ }^{2}$ Ryazan branch of Moscow University named after S.Y. Vitte, Pervomaisky avenue, 62, Ryazan, \\ 390013, Russia \\ ${ }^{3}$ University of the Prosecutor's Office of the Russian Federation, str. Azovskaya, 2, bld. 1, Moscow, \\ 117638 , Russia
}

\begin{abstract}
One of the institutions of criminal law, which is of undoubted interest among forensic scientists, are the circumstances precluding the criminality of an act. This interest is due to the controversy of certain legislative provisions, entailing the prosecution of persons acting under the conditions of the legality of these circumstances. When characterizing the circumstances precluding the criminality of an act, included in Ch. 8 of the Criminal Code of the Russian Federation, the law enforcement officer always proceeds from the assessment of the harm already caused to the interests protected by law and on the compliance of the harm with the conditions enshrined in the law. Acts committed in a state of circumstances precluding criminality are legally significant, since the law associates the emergence of two types of legal relations with these circumstances. In the first case, circumstances change the criminal-legal nature of the act and transfer it to the category of unpunished, despite causing harm. In the second, in the presence of circumstances in conditions of violation of the legality of an action (inaction), the harm caused is qualified as a crime. This necessitates a criminal-legal assessment of the harm caused from the standpoint of the theory of corpus delicti. At the same time, the substantiation of the legality of the actions of a person under the conditions of the circumstances precluding the criminality of an act is established by identifying in his action the signs of the corpus of lawful infliction of harm. The need for a structural analysis of the composition of the lawful infliction of harm is primarily due to the need to distinguish between certain types of circumstances that exclude crime, in order to correctly qualify the committed acts and prevent unjustified criminal prosecution for its infliction. The corpus of the lawful infliction of harm should be considered by highlighting the objective and subjective signs of the circumstances precluding the criminality of an act by analyzing the object, objective side, subject and subjective side of an act.
\end{abstract}

${ }^{*}$ Corresponding author: novikova@yandex.ru 


\section{Introduction}

The Criminal Code of the Russian Federation establishes six circumstances precluding the criminality of an act that are united in one chapter, although by their legal nature they can hardly be combined. As the interpretation of statistical data on the activities of courts of general jurisdiction shows, a number of initiated criminal cases are terminated or acquittals are issued in them in connection with the existence of circumstances precluding the criminality of an act.

It is advisable to carry out a structural analysis of the circumstances precluding the criminality of an act through the prism of the theoretical model of the "corpus delicti". That is to say, it is necessary to single out the objective and subjective signs of the circumstances precluding the criminality of an act, which will allow to isolate each of them and, on the basis of this, formulate the basis for qualifying these acts.

The purpose of the study is to develop recommendations for structuring the main elements of the corpus of lawful infliction of harm in order to qualify the committed acts on the basis of circumstances precluding the criminality of an act.

To achieve this goal, it is necessary to solve the following tasks:

- to study the typology of legal models for the formation of the system of circumstances precluding the criminality of an act;

- to substantiate the need to consider the circumstances precluding the criminality of an act through the prism of the category "corpus of the lawful infliction of harm";

- make a structural analysis of the lawful infliction of harm under circumstances precluding the criminality of an act.

- to study the statistical data of the Judicial Department at the Supreme Court of the Russian Federation on the practice of considering criminal cases on circumstances precluding the criminality of an act in the activities of federal courts of general jurisdiction and justices of the peace for the period from 2016 to the 1 st half of 2020, as well as court decisions in criminal cases on exceeding the limits of the circumstances precluding the criminality of the act.

\section{Methods}

Consideration of the circumstances precluding the criminality of the act through the prism of the composition of lawful infliction of harm in different periods was studied by Y.V. Baulin [1], G.S. Kurbanov [2], G.V. Nazarenko [3], V.V. Merkuriev [4], V.V. Baburin [5, 6], A.I. Sitnikova [7] and others. On the basis of objective and subjective signs of acts committed in the presence of circumstances precluding criminality of an act, differentiation is carried out, which is necessary for the correct qualification of the committed acts.

The research methodology is built on the basis of an analysis of the current criminal legislation, theoretical provisions on the definition, types and corpuses of the lawful infliction of harm in the presence of circumstances precluding the criminality of an act, as well as the practice of bringing to criminal responsibility or release from it for committing acts in the presence of circumstances precluding the criminality of an act by courts of general jurisdiction. The systematization of various points of view on individual problems of the structure of the circumstances precluding the criminality of an act was carried out, intermediate and final conclusions were formulated on the structure of the corpus of the lawful infliction of harm. The tools used made it possible to make proposals on the creation of a model of the circumstances of lawful infliction of harm in situations of necessary defense, extreme necessity, detention of a person who committed a crime, as well as justified risk. 


\section{Results}

The study on the issue of the structural analysis of circumstances precluding the criminality of an act allowed us to formulate conclusions that the consideration of these circumstances must be carried out through the prism of the corpus of the lawful infliction of harm. The allocation of objective and subjective signs of the corpus of individual circumstances that exclude the criminality of an act makes it possible to clearly distinguish between them, which, of course, is necessary in the process of qualifying acts that have caused harm to social relations protected by criminal law in the presence of circumstances precluding the criminality of an act.

Analysis of statistical data on the activities of federal courts of general jurisdiction and justices of the peace for the period from 2016 to the 1 st half of 2020 made it possible to present the dynamics of the commission of acts under circumstances precluding the criminality of an act (see: diagram 1), as well as data on the types of decisions taken in criminal cases on crimes under Art. 108 (murder in excess of the limits of necessary defense or in excess of the measures necessary for detention of a person who committed a crime) and Art. 114 of the Criminal Code of the Russian Federation (deliberate infliction of grave and moderate harm to health when the limits of necessary defense are exceeded or when the measures necessary to arrest the person who committed the crime are exceeded) (see: diagrams 2, 3).

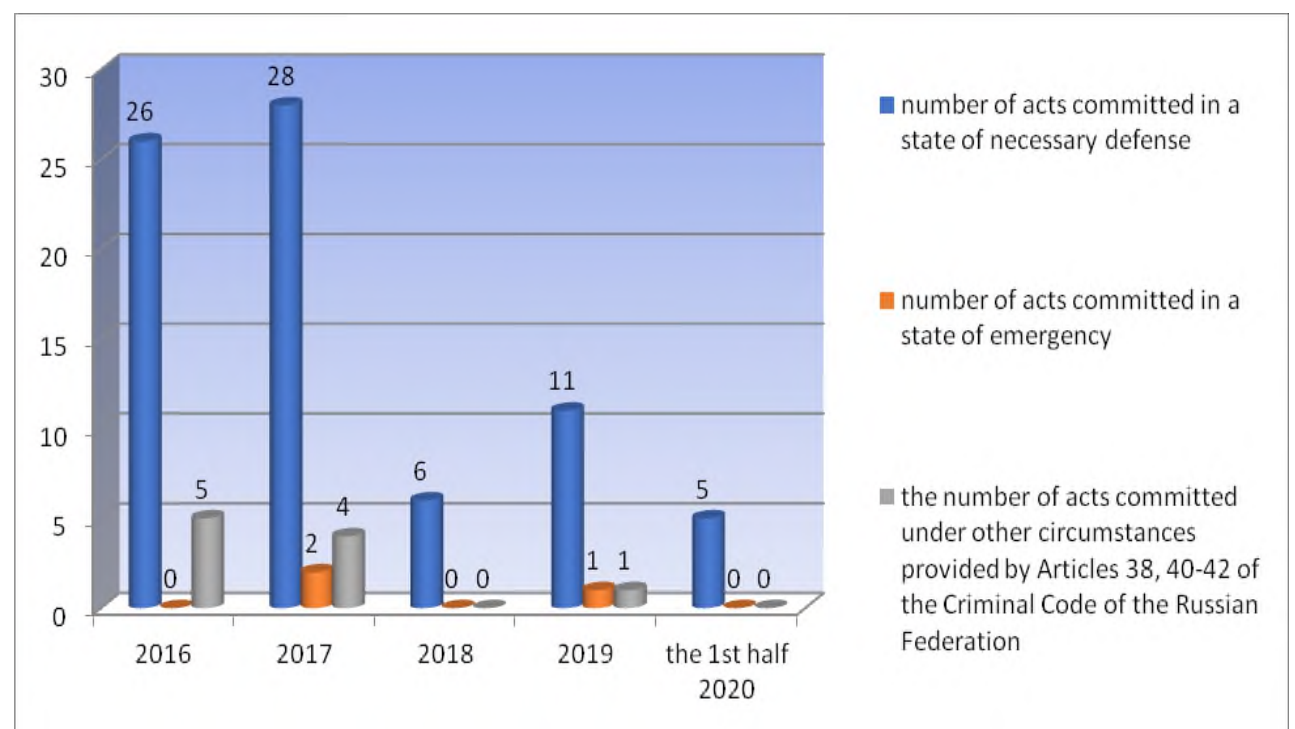

Fig. 1. The dynamics of the commission of acts in the presence of circumstances precluding criminality, in the period from 2016 to the 1 st half of 2020 . 


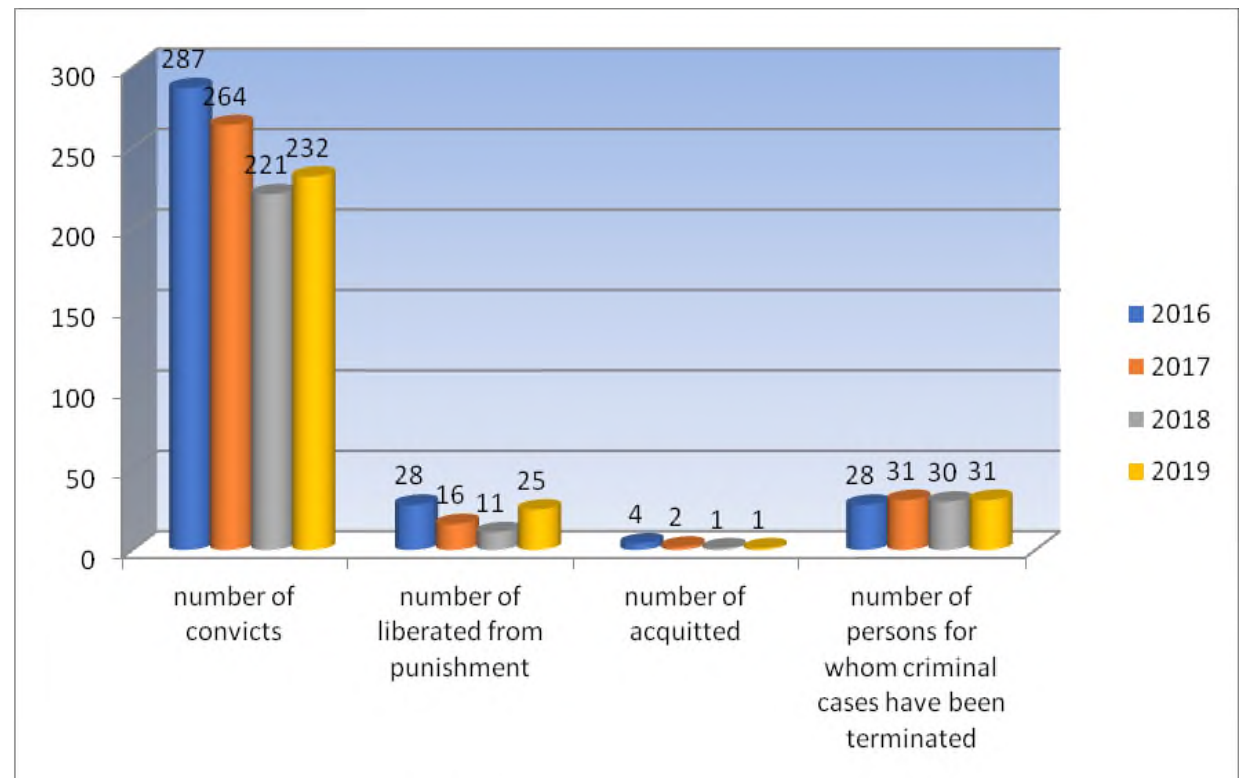

Fig. 2. Types of decisions made in criminal cases on crimes under Art. 108 of the Criminal Code of the Russian Federation in the period from 2016 to 2019 with the number of persons in respect of whom these decisions were made.

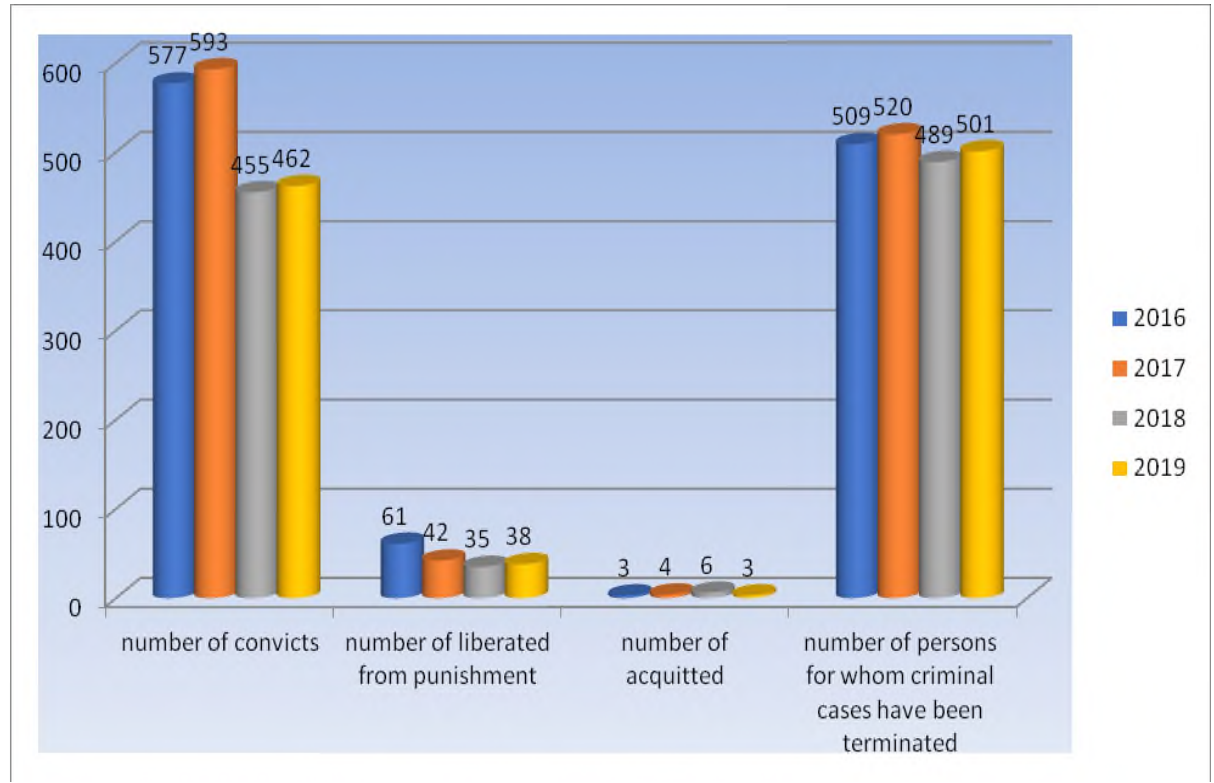

Fig. 3. Types of decisions made in criminal cases on crimes under Art. 114 of the Criminal Code of the Russian Federation in the period from 2016 to 2019 with the number of persons in respect of whom these decisions were made.

\section{Discussion}

In the theory of criminal law, under the circumstances precluding the criminality of an act, due to the absence of unlawfulness and guilt, action (inaction), although outwardly similar 
to those provided by criminal legislation and expressed in causing harm to law-protected interests, are understood, but committed by a person while realization of their subjective right, fulfilling legal obligation or performance of official duty in compliance with the conditions of their legality [8]. A.A. Ter-Akopov notes that the circumstances precluding the criminality of an act are divided into two groups: firstly, the circumstances indicating the absence of signs of a crime; secondly, indicating not the absence in the act of this or that sign of a crime, but the legality of the commission of the act provided by the Criminal Code of the Russian Federation, even if it involves causing harm [9]. When characterizing the circumstances precluding the criminality of the act provided in Ch. 8 of the Criminal Code of the Russian Federation, we always proceed from the assessment of harm already caused to the interests and public relations protected by law, on the compliance of its infliction with the conditions of legality enshrined in the law.

A.T. Veltmander notes that the typology of legal models for the formation of a system of circumstances precluding the criminality of an act depends on the content of their constituent elements, the way they are consolidated, their relationships with criminal acts and on some other features [10].

There are at least four approaches to the way of fixing these circumstances in the criminal legislation of different legal systems: 1) consolidation in an independent chapter, apart from other grounds excluding criminal liability, and other legal categories, as is done in the Criminal Code of the Russian Federation; 2) inclusion of circumstances precluding the criminality of an act in one chapter with other circumstances excluding criminal liability, or with other legal categories; 3) separate consolidation of the circumstances precluding the criminality of an act in several chapters, paragraphs, due to the lack of general principles of their association with other legal categories; 4) a mixed method of legislative consolidation of circumstances precluding the criminality of an act, which has several of the three previously described methods of consolidation [10].

The Criminal Code of the Russian Federation establishes six circumstances precluding the criminality of an act united in one chapter, although by their legal nature they can hardly be combined.

In order to determine the place of one of the circumstances precluding the criminality of an act among others, it seems to us necessary, on the basis of the signs and conditions of lawfulness highlighted in criminal legislation and the theory of criminal law, to distinguish between the most similar circumstances. It is advisable to carry out a structural analysis of the circumstances precluding the criminality of an act through the prism of the corpus of these acts, similar to the theoretical model of the "corpus delicti". That is, it is necessary to single out the objective and subjective signs of the circumstances precluding the criminality of an act, which will allow to isolate each of them and, on the basis of this, formulate the basis for qualifying these acts.

As the interpretation of statistical data on the activities of courts of general jurisdiction shows, a number of initiated criminal cases are terminated or acquittals are issued in them in connection with the existence of circumstances precluding the criminality of an act.

So, in 2016, under circumstances precluding criminality, 31 acts were committed, initially qualified as a crime, of which 26 were in a state of necessary defense and 5 under other circumstances excluding crime, provided in Art. 38, 40-42 of the Criminal Code of the Russian Federation. In 2017, the number of acts committed under circumstances precluding criminality was 34 , of which 28 were committed in a state of necessary defense, 2 - in a state of extreme necessity, 4 - under other circumstances excluding the criminality of an act provided in Art. 38, 40-42 of the Criminal Code of the Russian Federation. In 2018, the number of acts of this category decreased significantly and amounted to only 6 acts, all of which were committed in a state of necessary defense. In 2019, 13 acts were committed under circumstances precluding criminality, of which: 11 acts were committed 
in a state of necessary defense, 1 - in a state of extreme necessity, 1 - under other circumstances excluding crime, provided for in Art. 38, 40-42 of the Criminal Code of the Russian Federation. In the first half of 2020, the number of acts in this category was 5, all of which were committed in a state of necessary defense [11] (see: Diagram 1).

It should be emphasized that the proportion of acts committed under circumstances precluding criminality are crimes against life and health (Articles 105, 108, 111, 113, 114, 115,116 of the Criminal Code of the Russian Federation). The above data indicate that in practice, acts committed under circumstances precluding the criminality of an act are initially classified by law enforcement agencies as crimes, and only after the consideration of criminal cases by the courts, the proceedings on the cases are terminated and persons are released from criminal liability for lawful infliction of harm. This fact proves the need to consider individual circumstances that exclude the criminality of an act in order to understand their content.

For the correct qualification of acts that have caused harm to the interests protected by the criminal law, in a state of necessary defense, extreme necessity, a situation of detention of a person who has committed a crime, a reasonable risk, and their differentiation among themselves, it is necessary to conduct a structural analysis of the corpus of these circumstances of causing harm and find out:

- their focus;

- sources giving rise to harm;

- the circle of subjects entitled to harm in these conditions;

- the degree of preparation of an act;

- the ability to achieve a goal in the current situation without causing harm and under the conditions of the implementation of subjective rights created by the person;

- the targeting of harm (otherwise, the victim of an act);

- the amount of possible harm, its ratio with the result expected from the actions caused by the application of a circumstance that excludes the criminality of an act, and the amount of actually caused harm (as a consequence of a committed act);

- the form of fault when the limits are exceeded [12].

All these signs can be grouped according to the elements of the circumstances precluding the criminality of an act and highlight the objective and subjective signs of these circumstances.

In the theory of criminal law, the approach to the consideration of the circumstances precluding the criminality of an act through the prism of the corpus of the lawful infliction of harm is not new. As noted by V.V. Baburin, E.I. Buevich, the idea of the corpus of the circumstances precluding the criminality of the act was not considered for a long time due to the fact that the same conditions of legality were included in the content of circumstances precluding the criminality of the act. The corpus of the circumstances precluding the criminality of the act began to play in a new light after experts began to consider its elements and signs by analogy with the "corpus delicti" [13].

From the standpoint of the composition of the lawful infliction of harm in the presence of the circumstances precluding the criminality of an act, the necessary defense, harm caused during the arrest of a person who committed a crime, extreme necessity, and reasonable risk were considered.

In the theory of criminal law, there are two approaches to determining the corpus of the circumstances precluding the criminality of an act, depending on what the authors include in the content of such a corpus. The first group of authors focuses on the content of the circumstances in which the person acts, highlighting the features that characterize the encroachment, protection and harm caused, and excludes the possibility of their consideration through a set of objective and subjective features and acts [14]. The second group, on the other hand, considers the corpus of the circumstances precluding the 
criminality of an act as a set of elements that make up the act of the subject causing legitimate harm, including exceeded limits [2].

A.I. Sitnikova understands the composition of lawful (non-criminal) infliction of harm as a set of features that exclude the criminality of an act in cases of harm to objects of criminal law protection in exceptional situations. She points out the elements of the designated corpus: the basis for the commission of actions (inaction), the object of protection, the purpose of causing harm, the method of actions (inaction) in time and the conditions for the legality of causing harm [7].

Unlike her, V.V. Merkuryev understands the corpus of the necessary defense as a circumstance precluding the criminality of an act, he understands "a differentiated legal fact-state, which is a system of interrelated and interacting features that characterize its object, objective side, subject, subjective side, the presence of which forms a legal basis for excluding criminal liability for harm caused to the infringing person" [4].

Analyzing the existing theoretical provisions on the corpus of the lawful infliction of harm under circumstances precluding the criminality of an act, we note that the composition of the lawful infliction of harm means the system of objective and subjective signs established by the criminal law, necessary and sufficient to establish in each case of a socially dangerous act of signs of lawful harm provided for by specific Art. ch. 8 of the Criminal Code of the Russian Federation. As part of the legitimate harm to any of the circumstances precluding the criminality of the act, four elements should be distinguished: the object, the objective side, the subject and the subjective side of the defender's behavior.

The object of lawful infliction of harm under the circumstances precluding the criminality of an act is public relations protected by criminal law, which are harmed as a result of the implementation of a circumstance that excludes crime. In addition, when assessing the object, it is necessary to determine the category of persons who may be harmed as a result of an act. For example, with the necessary defense, harm can only be inflicted on the encroaching person, and upon arrest, the person who committed the crime.

For example, dual social relations are the object of lawful infliction of harm with necessary defense. On the one hand, these are public relations protected by the defenders, which are encroached upon by the attacker, on the other, public relations related to the interests of the attacker.

In our opinion, the object of lawful infliction of harm with necessary defense is social relations protected by criminal law, ensuring the personal interests of the encroaching person who was harmed by the lawful actions of the defending subject.

The object of lawful harm during the arrest of a person who has committed a crime is public relations protected by criminal law, which was harmed by a committed socially dangerous act or a real threat of harm is created, as well as the life and health of the detained person [15].

The objective side of acts that exclude crime is the external side of the process of lawful infliction of harm and includes: the act of a person realizing rights or performing duties, the consequences in the form of harm caused as a result of the committed act, the causal relationship between the act and the harm caused, as well as the situation under the circumstances precluding the criminality of an act in which the subject acts.

The objective side of the circumstances precluding the criminality of an act is the external characteristic of the lawful infliction of harm, which consists in a socially dangerous act stipulated by the criminal law, naturally causing harm, within the limits provided for by the norms, in the setting of a specific circumstances.

With a reasonable risk, the person's actions are aimed not at eliminating direct harm, but at achieving a positive result, that is, at changing the current situation, "harmful" in relation to the expected progress [16]. Hence, it follows that the source that generates a risk situation are the acts of the riskiest subject, carried out within the limits of admissibility. 
Risk is the permissible behavior of a person, which he has the right to carry out or refuse to carry it out, depending on the situation at the time of making a decision.

The impossibility or difficulty of achieving the goal in a non-risky way is also taken into account, although there is a possibility of choosing a behavior option.

The subject of lawful harm infliction in the case of circumstances precluding the criminality of an act can only be an individual who has the characteristics of a subject of a socially dangerous act prohibited by criminal law. Thus, the subject of necessary defense can be any person who actually carries out the suppression of an attack, regardless of being a professional and having special training and service position. The subject of justified risk must be a professional in his field, that is, be a qualified specialist or systematically carry out a certain kind of activity, as a result of which he develops sufficient skills and abilities to improve his activities, albeit in a risky way. In this regard, the risk subject is able to take measures to counter possible harm.

The recipient of risk shall take sufficient measures to prevent harm caused by the risk. That is, he must, foreseeing the possible negative consequences of his action, calculate the prospects for the development of a risk situation and develop various options for countering their happening. After that, implement the most prepared and appropriate option for the situation.

It should be noted that risky actions can harm any interests protected by law within the limits established by law. However, it is strictly forbidden to commit acts that may knowingly entail the onset of grave consequences, such as the death of many people, an environmental disaster or a public disaster. In this case, the person who committed risky actions is subject to criminal liability on a general basis.

The subjective side of the circumstances precluding the criminality of an act characterizes the mental attitude of a person to the act he is committing, aimed at the realization of rights or the fulfillment of assigned duties under the circumstances precluding the criminality of an act, which is characterized by a specific form and purpose. For example, given a reasonable risk, in order to justify risky actions, it is necessary that they are to be aimed at achieving a socially useful goal. The orientation of the act towards a socially useful goal, subject to the fulfillment of other conditions of legality, makes the act of the person permissible.

\section{Conclusion}

The study on the issues of the structural analysis of the composition of circumstances excluding the criminality of an act allowed us to formulate the following conclusions:

1 ) it is advisable to carry out the structural analysis of the circumstances precluding the criminality of an act through the prism of the theoretical model of "corpus delicti". That is, it is necessary to highlight the objective and subjective characteristics of the circumstances, which will allow to isolate each of them and formulate the basis for qualifying these acts;

2) the corpus of the lawful infliction of harm should be understood as the system of objective and subjective signs established by the criminal law, necessary and sufficient for the establishment in each case of a socially dangerous act of signs of lawful infliction of harm, provided for by a specific article of Ch. 8 of the Criminal Code of the Russian Federation;

3) four elements should be distinguished as part of the lawful infliction of harm to any of the circumstances precluding the criminality of an act: the object, the objective side, the subject and the subjective side of the defender's behavior;

4) the object of lawful infliction of harm under circumstances precluding the criminality of the act is public relations protected by criminal law, which are harmed as a result of the implementation of a circumstance that excludes crime. In addition, when assessing the 
object, it is necessary to determine the category of persons who may be harmed as a result of the act. For example, with necessary defense, harm can only be inflicted on the encroaching person, but upon arrest, the person who has committed a crime;

5) the objective side of acts that exclude criminality is the external side of the process of lawful infliction of harm and includes: the act of a person exercising rights or performing duties, the consequences in the form of harm caused as a result of the committed act, the causal relationship between the act and the harm caused, as well as the situation under circumstances precluding the criminality of the act in which the subject acts;

6) the subject of causing legitimate harm in the case of circumstances precluding the criminality of the act can only be an individual who has the characteristics of a subject of a socially dangerous act prohibited by criminal law;

7) the subjective side of the circumstances precluding the criminality of the act characterizes by the mental attitude of a person to the act he is committing, aimed at the realization of rights or the fulfillment of the assigned duties under circumstances precluding the criminality of the act, which is characterized by a specific form and purpose;

8 ) the allocation of objective and subjective signs of the composition of the lawful infliction of harm is necessary for the correct qualification of committed acts that exclude crime.

\section{References}

1. Y.V. Baulin, Circumstances precluding the criminality of an act. (Osnova, Kharkov, 1991)

2. G.S. Kurbanov, Circumstances eliminating public danger and unlawfulness of an act (Ganjilik, Baku, 1991)

3. G.V. Nazarenko, Actual problems of criminal law (Orel, 1991)

4. V.V. Merkuriev, The composition of the necessary defense (Publishing house of R. Aslanov "Legal Center Press", SPb, 2004)

5. V.V. Baburin, Omsk Scientific Bulletin 5 (2006)

6. V.V. Baburin, Questions of legal theory and practice: interuniversity scientific collection (Omsk Academy of the Ministry of Internal Affairs of Russia, Omsk, 2011)

7. A.I. Sitnikova, LEX RUSSICA 8(117), 48-61 (2016)

8. N.S. Martynova, Circumstances excluding the criminality of an act: Lecture (VIPK of the Ministry of Internal Affairs of Russia, Domodedovo, 2001)

9. A.A. Ter-Akopov, Crime and problems of non-physical causality in criminal law ("YURKNIGA", M., 2003)

10. A.T. Veltmander, Criminal Justice 2(2), 11-14 (2013)

11. Summary statistical information on the state of convictions in Russia for 2016, 2017, 2018, 2019 and the 1st half of 2020. Form No. 10.3. Report on the types of punishment for the most serious crime (excluding addition), http://www.cdep.ru/index.php?id=79

12. S.S. Zakharova, Reasonable risk in the criminal law of the Russian Federation: diss. ... Cand. jurid. sciences (Ryazan, 2005)

13. V.V. Baburin, E.I. Buevich, Bulletin of Omsk University. Series "Law" 2(39), 184-190 (2014)

14. E.V. Blagov, State and law 9, 79 (1992)

15. V.A. Ishmukhametova, Bulletin of Omsk University. Series "Right" 2(39), 218-223 (2014) 
16. V.L. Zuev, A necessary defense and an urgent need. Qualifications and forensic practice ("Krosna-Lex", M., 1996)

17. V.F. Lapshin, S.A. Korneev, E3S Web of Conferences 135, 04063 (2019) DOI: 10.1051 / e3sconf / 201913504063

18. A.A. Brovkina, V.E. Vezlomtsev, S.S. Zakharova, O.A. Shuranova, Yu.V. Truntsevsky, E3S Web of Conferences 135, 04066 (2019) DOI: 10.1051 / e3sconf / 201913504066 